\title{
Editorial
}

Digestion

Published online: November 23, 2005

\section{Differences in Incidence and Distribution of Colorectal Cancer among Races and Ethnic Societies: Lifestyle, Genes or Both?}

\author{
Menachem Moshkowitz Nadir Arber \\ Integrated Cancer Prevention Center, Tel Aviv Medical Center and Tel Aviv University, Tel Aviv, Israel
}

The onset of colorectal cancer (CRC) is less an 'event' than the result of successive 'stages' in the protracted process of colorectal carcinogenesis. CRC is the fourth most common incident cancer and the second leading cause of cancer death in Western societies [1]. Incidence rates vary approximately 20 -fold around the world, with the highest rates seen in the developed world and the lowest rate in India $[2,3]$. The international differences, migrant data, and recent rapid changes in incidence rates in several countries show that CRC in particular is highly sensitive to environmental changes. Among immigrants and their descendants, incidence rates rapidly reach those of the host country, often even with the first generation of immigrants $[5,6]$.

Among Jews in Israel, CRC is the leading cause of death from cancer, while the Palestinian population appears to be protected from it [7]. It has long been noted that Israelis of European origin are more susceptible to CRC than Asian-African born Jews (42/100,000 vs. $25 / 100,000$, respectively, mean age standardized rates for 1989-1993) [7]. Studies from the US and Australia have also corroborated the findings that Jewish populations, particularly those of European origin, are at high risk for $\mathrm{CRC}$ [8]. The incidence of the disease among Palestinians is estimated to be $7 / 100,000$, approximately one-fifth that of Jews in Israel [7].

The study of Fireman et al. [9] in this issue of Digestion confirmed their previous observation [10]: the inci- dence of CRC in central Israel is significantly lower in the Arab population compared with the Jewish citizens, for both males and females, and that this diversity has not changed during the last two decades. They also found that, in the Arab population, CRC tends to be right sided. Similar findings have been reported by other investigators [11].

The genetic background of Jews and Arabs is almost identical: the two groups share common prehistoric ancestors and have a common geographic and ecological milieu. Israel is therefore an ideal testing ground for these concepts because of a well-defined population of subgroups that have retained their ethnicity. The intra-population variations in incidence, morbidity and mortality suggest that at least some genetic differences partially account for these obvious differences in the degree of susceptibility to CRC. Furthermore, there is a genetic susceptibility for germ line predominant mutations among the Jewish population for developing breast (BRCA 1,2 mutations) and colon (APC) cancers, which are known in the literature as the Ashkenazi Jewish mutations. It is also possible that lifestyle differences, and in particular differences in diet, may be a protecting factor among Palestinians (as in the economically under-developed world), and a risk factor among the Ashkenazi Jews (as in the economically developed world).

Our group [12] conducted a molecular epidemiology study in order to compare molecular genetic differences

\section{KARGER \\ Fax +4161306 1234 E-Mail karger@karger.ch} www.karger.com
C 2005 S. Karger AG, Basel 0012-2823/05/0724-0219\$22.00/0

Accessible online at: www.karger.com/dig
Menachem Moshkowitz

Department of Cancer Prevention, Tel Aviv Medical Center

6 Weizmann St.

Tel Aviv 64239 (Israel)

Tel. +972 3697 4968, Fax +972 3695 0339, E-Mail narber@post.tau.ac.il 
among three ethnic groups with different risk for CRC: high risk (Ashkenazi Jews), intermediate risk (Sephardic Jews) and low risk (Palestinians), all living in the same geographical region. The levels of cyclin D1, $\beta$-catenine, p27, p53, Ki-67 and Her-2/neu proteins were determined by immunohistochemistry. Ashkenazi Jews had the highest rate of CRC, but it was diagnosed at an early stage compared to Palestinians (72 and 33\% of the cases are in Duke's A and B, respectively). The Sephardic Jews were diagnosed at an intermediate stage, the tumors are poorly differentiated and they lack p27. Palestinians had significantly higher cyclin D1 levels; there was a statistically significant inverse correlation between the expression of $\beta$-catenine and cyclin D1, as well as p53 and p27 (p < 0.05 ). The lower mortality rate among Ashkenazi Jews may be partially explained by their better molecular biology profile.

Interestingly, similar differences in cancer incidence, age of onset and localization along the colon have been reported among other multi-ethnic communities around the world. These include Asian-Pacific immigrants and African Americans in the US [13].

CRC is a multi-factorial disease. It is a result of a timedependent accumulation of mutations in genes controlling colonic epithelial cell turnover, and its incidence depends on both genetic as well as environmental risk factors, such as diet and lifestyle behavior. It is therefore not surprising to find various differences in prevalence, age of onset and anatomical distribution among various international populations and intra-national ethnic groups.

Data from other Arab communities such as Jordan [14] and Oman [15] also revealed low incidence of CRC. These differences may reflect the influence of culture and socioeconomic differences in dietary habits, obesity, use of tobacco, alcohol consumption, physical activity, genetic background and gene-environment interactions [16-18]. Dietary factors are likely to have a major influence on risk of CRC. Migrant studies of dietary intake and dietary acculturation support the concept that with a shift to Western countries, CRC incidence rates rise toward the risk levels of the host countries [19,20].

Although the results of the first Israeli national health and nutrition survey have not yet been published [21], there is evidence that the dietary patterns of the Jewish and Arab population groups differ in many important aspects [22]. The diet of traditional Arab societies is characterized by a high-fiber content and is low in fat and cholesterol. It consists also of a high intake of olive oil. Recent studies have shown that diets rich in olive oil, a
Mediterranean diet, might have a protective effect against CRC $[23,24]$.

Most of the Arab population in the Middle East, especially in Israel, faced marked changes in demographic, socioeconomic and health situations during the last 3-4 decades. These include several cultural changes associated with modernization, diet and physical activity. However, this time interval may be too short to manifest significant increase in cancer incidence. This explains also the lack of difference in CRC pattern between the current [10] and the previous studies [9].

Genetic differences between Jews and Arabs may also account for the differences in the incidence of CRC. Studies from Israel and the United States have shown that the Jewish population, particularly those of European origin, is at the highest risk for CRC [25]. Furthermore, a genetic susceptibility for germ line predominant mutations for the development of breast (BRCA 1,2 mutations) and colon $(A P C)$ cancers have been described among the Jewish population, and are known as the Ashkenazi Jewish mutations [26]. Some specific mutations have been described also in the Arab community [27].

Another important aspect of CRC is its anatomical site of origin. In general, the developed countries have a predominance of left-sided cancers, whereas low-risk communities have a higher proportion of right-sided cancers. Many hypotheses have been put forward to explain the differences in the epidemiological patterns of CRC among various populations. They are based on histological, functional and genetic differences between the left and right colon. Proximal and distal sections of the colon have different embryologic origins and morphology. The proximal colon is primarily involved with water absorption and solidification of fecal contents, while the left colon stores the stool. Hence, there are differences in the sensitivity and exposure to carcinogens. Indeed, in an animal model, it had been shown that different carcinogens induce cancers in different parts of the large bowel [28].

An epidemiologic case-control study has shown that intake of red meat and processed meat was associated with increased risk of proximal CRC in men [29]. In another study, egg consumption had been associated with proximal CRC in females, suggesting a role for cholesterol in the etiology of proximal CRC [30]. Cholecystectomy has also been associated with an elevated risk of proximal CRC. Changes in the intestinal exposure to bile acids have been suggested as the primary biological mechanism [31], and in particular certain bile acid metabolites selectively increase the risk of proximal colon cancer [32]. High level of secondary bile acids may increase the rate 
of cell proliferation within the intestinal crypt and promote the development of cancer [33]. Despite all this data, the associations of diet and lifestyle with risk of proximal CRC have not been consistently observed in epidemiologic studies, suggesting that this phenomenon may be related to other concurrent risk factors. It has been speculated that genetics may also play a more important role in the genesis of proximal CRC [34].

Unlike proximal colon cancer, abundant epidemiologic studies have reported positive associations of high alcohol intake, tobacco smoking, red meat intake, and high serum albumin with increased risk of rectal cancer. These studies have also reported the protective effects on the risk of distal colon cancer and in particular rectal cancer for: high intake of fruit, vegetable and fibers, increased physical activity; a higher percentage of calories derived from carbohydrate and a high intake of iron and calcium $[35,36]$. Nonetheless, the impact of racial differences in the milieu of risk and protecting factors for CRC is little.

The importance of conducting studies to investigate differences in the incidence and sub-site of CRC among races and genders is driven by two important reasons. First, CRC is a major health concern and it is a multifactorial disease, with complex interactions between genetic and environment factors. Secondly, knowledge of such differences might help in formulating the right preventive strategies and perhaps guide research in the direction of more effective and less toxic therapies.

\section{References}

1 Ries LA, Wingo PA, Miller DS, Howe HL, Weir HK, Rosenberg HM, Vernon SW, Cronin $\mathrm{K}$, Edwards BK: The annual report to the nation on the status of cancer, 1973-1997, with a special section on colorectal cancer. Cancer 2000;88:2398-2424.

2 World Health Organization: The World Health Report. Geneva, WHO, 1997.

3 Parkin DM, Muir CS, Whelan SL, Gao JT, Ferlay J, Powell J: Cancer Incidence in Five Continents. Lyon, IARC Press, 1992.

4 Muir C, Waterhouse J, Mack T, Powell J, Whelan S, Smans M, et al: Cancer Incidence in Five Continents. Lyon, IARC Press, 1987.

5 McMichael AJ, Giles GG: Cancer in migrants to Australia: extending the descriptive epidemiological data. Cancer Res 1988;48:751756.

6 Haenszel W: Cancer mortality among the foreign-born in the United States. J Natl Cancer Inst 1961;26:37-132.

7 Israel Cancer Registry: Cancer in Israel. Jerusalem, Ministry of Health, 1997.

8 Rozen P, Lynch HT, Figer A, et al: Familial colon cancer in the Tel-Aviv area and the influence of ethnic origin. Cancer 1987;60:23552359.

9 Fireman Z, Neiman E, Abu Moch S, Kopelman Y: Trends in incidence of colorectal cancer in Jewish and Arab populations in central Israel. Digestion 2005;72:223-227.

10 Fireman Z, Sandler E, Kopelman Y, Segal A, Sternberg A: Ethnic differences in colorectal cancer among Arab and Jewish neighbors in Israel. Am J Gastroenterol 2001;96:204-207.

11 Barchana M, Liphshitz I, Rozen P: Trends in colorectal cancer incidence and mortality in the Israeli Jewish ethnic populations. Fam Cancer 2004;3:207-214.
12 Darwish H, Trejo LE, Zughier M, Shaked M, Alon-Baron L, Hibshoosh H, Sweidan W, Halpern Z, Arber N: Fighting colorectal cancer through collaboration: molecular epidemiology differences among Palestinians, Ashkenazi and Sephardic Jews. Ann Oncol 2002;13: 1497-1501.

$13 \mathrm{Wu}$ X, Chen VW, Martin J, et al: Subsite-specific colorectal cancer incidence rates and stage distributions among Asians and Pacific Islanders in the United States, 1995 to 1999. Cancer Epidemiol Biomarkers Prev 2004; 13:12151222.

14 Freedman LS, Barchana M, Al-Kayed S: A comparison of population-based cancer incidence rates in Israel and Jordan. Eur J Cancer Prev 2003; 12:359-365.

15 al-Lawati JA, Santhosh-Kumar CR, Mohammed AJ, Jaffer MA: Cancer incidence in Oman, 1993-1997. East Mediterr Health J 1999;5: 1035-1041.

16 Vanio H, Bianchini F: IARC Handbook of Cancer Prevention, vol 6: Weight Control and Physical Activity. Lyon, IARC Press, 2002.

17 Le Marchand L, Wilkens LR, Kolonel LN, Hankin JH, Lyu LC: Associations of sedentary lifestyle, obesity, smoking, alcohol use, and diabetes with the risk of colorectal cancer. Cancer Res 1997;57:4787-4794.

18 Flood A, Velie EM, Chaterjee N, et al: Fruit and vegetable intakes and the risk of colorectal cancer in the Breast Cancer Detection Demonstration Project follow-up cohort. Am J Clin Nutr 2002;5:936-943.

19 Shimizu H, Mack TM, Ross RK, Henderson $\mathrm{BE}$ : Cancer of the gastrointestinal tract among Japanese and White immigrants in Los Angeles County. J Natl Cancer Inst 1987;78:223228.
20 Stemmermann GN, Nomura AM, Chyou PH, Kato I, Kuroishi T: Cancer incidence in Hawaiian Japanese: migrants from Okinawa compared with those from other prefectures. Jpn J Cancer Res 1991;82:1366-1370.

21 Kaluski DN,Goldsmith R, Arie OM, Mayer C, Green M: The first Israeli national health and nutrition survey (MABAT) as a policy maker. Public Health Rev 2000;28:23-26.

22 Green MS: Differences between Israeli Jews and Arabs in morbidity and mortality rates for diseases potentially associated with dietary risk factors. Public Health Rev 1998;26:3140.

23 Schwartz B, Birk Y, Raz A, Madar Z: Nutritional-pharmacological combinations - a novel approach to reducing colon cancer incidence. Eur J Nutr 2004;43:221-229.

24 Bartoli R, Fernandez-Banares F, Navarro E, Castella E, Mane J, Alvarez M, Pastor C, Cabre E, Gassull MA: Effect of olive oil on early and late events of colon carcinogenesis in rats: modulation of arachidonic acid metabolism and local prostaglandin $\mathrm{E}(2)$ synthesis. Gut 2000;46:191-199.

25 Kune S, Kune GA, Watson L: The Melbourne colorectal cancer study: incidence findings by age, sex, site, migrants and religion. Int J Epidemiol 1986 15:483-493.

26 Rozen P, Shomrat R, Strul H, Naiman T, Karminsky N, Legum C, Orr-Urtreger A: Prevalence of the I1307K APC gene variant in Israeli Jews of differing ethnic origin and risk for colorectal cancer. Gastroenterology 1999;116: 54-57.

27 Chen-Shtoyerman R, Theodor L, Harmati E, et al: Genetic analysis of familial colorectal cancer in Israeli Arabs. Hum Mutat 2003;21: 446-447. 
28 Nelson RL, Dollear T, Freels S, Persky V: The relation of age, race, and gender to the subsites location of colorectal carcinoma. Cancer 1997; 80:193-197.

29 Le Marchand L, Wilkens LR, Hankin JH, Kolonel LN, Lyu LC: A case-control study of diet and colorectal cancer in a multiethnic population in Hawaii (United States): lipids and foods of animal origin. Cancer Causes Control 1997;8:637-648.

30 Steinmetz KA, Potter JD: Food-group consumption and colon cancer in the Adelaide Case-Control Study. 2. Meat, poultry, seafood, dairy foods and eggs. Int J Cancer 1993;53: 720-727.
31 Lagergren J, Ye W, Ekbom A: Intestinal cancer after cholecystectomy: is bile involved in carcinogenesis? Gastroenterology 2001;121:542547.

32 McMichael AJ, Potter JD: Host factors in carcinogenesis: certain bile-acid metabolic profiles that selectively increase the risk of proximal colon cancer. J Natl Cancer Inst 1985; 75 : 185-191.

33 Weisburger JH, Reddy BS, Rose DP, Cohen LA, Kendall ME, Wynder EL: Protective mechanisms of dietary fibers in nutritional carcinogenesis. Basic Life Sci 1993;61:45-63.
34 Bufill JA: Colorectal cancer: evidence for distinct genetic categories based on proximal or distal tumor location. Ann Intern Med 1990; 113:779-788.

35 Deneo-Pellegrini H, Boffetta P, De Stefani E, Ronco A, Brennan P, Mendilaharsu M: Plant foods and differences between colon and rectal cancers. Eur J Cancer Prev 2002;11:369-375.

36 Slattery ML, Curtin KP, Edwards SL, Schaffer DM: Plant foods, fiber, and rectal cancer. Am J Clin Nutr 2004;79:274-281. 